\title{
Organotin compounds in surface sediments from selected fishing ports along the Chinese coast
}

\author{
ZHANG KeGang ${ }^{1}$, SHI JianBo ${ }^{1 *}$, HE Bin ${ }^{1}$, XU WeiHai ${ }^{2}$, LI XiangDong ${ }^{3}$ \& JIANG GuiBin ${ }^{1}$ \\ ${ }^{1}$ State Key Laboratory of Environmental Chemistry and Ecotoxicology, Research Center of Eco-Environmental Sciences, Chinese Academy of \\ Sciences, Beijing 100085, China; \\ ${ }^{2}$ CAS Key Laboratory of Marginal Sea Geology, South China Sea Institute of Oceanology, Chinese Academy of Sciences, Guangzhou 510301, \\ China; \\ ${ }^{3}$ Department of Civil and Structural Engineering, the Hong Kong Polytechnic University, Hung Hom, Kowloon, Hong Kong, China
}

Received February 23, 2012; accepted April 23, 2012; published online August 16, 2012

\begin{abstract}
The concentrations and species of organotin compounds (OTCs) in 52 surface sediment samples from nine fishing ports along the Chinese coast were studied. Butyltins (BTs) and phenyltins (PhTs) were derivatized using sodium tetraethylborate $\left(\mathrm{NaBEt}_{4}\right)$ and determined by head-space solid-phase microextraction (HS-SPME) gas chromatography coupled with a flame photometric detector (GC-FPD). The concentrations of OTCs ranged from $<3.6$ to $194 \mathrm{ng}$ (Sn) $\mathrm{g}^{-1}$ dry weight (dw) for monobutyltin (MBT), $<2.3$

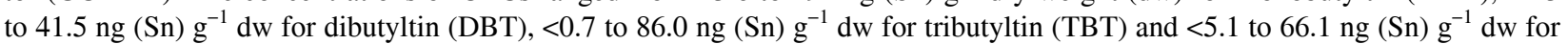
monophenyltin (MPhT), respectively. The concentrations of diphenyltin (DPhT) and triphenyltin (TPhT) were below the limit of detection (LOD). BTs were the main species in the sediments except for the samples collected from Shazikou fishing port in Qingdao. The concentrations of MBT were higher than DBT and TBT. The concentrations of OTCs in the sediments varied widely among different sampling locations. The concentrations of BTs were much higher in the samples collected from fishing ports close to the South China Sea than those in coast of the East China Sea and the Yellow Sea. MPhT was prevalent in most sampling stations except for those in coast of the East China Sea. The environmental and ecotoxicological risks of TBT in most sediment samples were low.
\end{abstract}

butyltin, phenyltin, fishing port, sediment

Citation: Zhang K G, Shi J B, He B, et al. Organotin compounds in surface sediments from selected fishing ports along the Chinese coast. Chin Sci Bull, 2013, 58: 231-237, doi: 10.1007/s11434-012-5406-6

During the last century, organotin compounds (OTCs) have been widely used as accelerators, polyvinyl chloride (PVC) stabilizers, biocides, coatings, wood preservatives and antifouling paints etc. As a result, they were introduced into the environment at large quantities [1]. Among organotin species, tributyltin (TBT), triphenyltin (TPhT) and their derivatives have been of particular concern because they were usually used as paint additives to prevent bio-fouling on ship hulls, marine platforms and fishing nets, which resulted in world-wide pollution in aquatic environments [2,3]. TBT can cause chronic and acute toxic effects to algae, zooplankton, mollusks, and some fish species even at very low

*Corresponding author (email: jbshi@ rcees.ac.cn) concentrations [4-6]. TPhT is less toxic than TBT, but can also be of high risk to aquatic life $[1,7]$.

In view of their high toxicity, control measures on OTCs have been made in many parts of the world, especially in developed countries [1]. A total ban of TBT proposed by the International Maritime Organization (IMO) has taken effect since January 2008 [8]. The United Nations Environment Programme (UNEP) and Food and Agriculture Organization of the United Nations (FAO) added the pesticide TBT to a global trade "watch list" after the Rotterdam Convention in November 2008 [9]. However, OTCs were still used and discharged into aquatic systems, especially in developing countries where monitoring and inspection were less well established [3,10-12]. 
Coastal zones, including harbors, are usually seriously polluted areas of OTCs because of intensive human activities and heavy marine traffic $[13,14]$. Fishing port is a harbor or a part of harbor for landing and distributing ocean products, where OTCs could be released not only from antifouling coatings on vessels, but also from many land sources, such as manufacture and maintenance of fishery-related facilities. The organotin pollution in Chinese costal zones has been reported in several studies [15-18]. Cao et al. [16] reviewed the distribution of BTs in sediments and found that the concentrations were high in locations with many shipping activities, such as Hong Kong, Shenzhen and West Harbor in the Jiulongjiang estuary. The pollution has resulted in the accumulation of BTs in marine biota and some mollusks species $[17,19]$. However, fishing ports were largely ignored in most studies.

Sediment can reflect the pollution of OTCs in the coastal water environment for their high accumulation and slow degradation processes [20-23]. Sediment may become a significant source of organotin pollution during the dredging, and disposal of contaminated sediment, which has been involved in the IMO ban. In addition, organotin in sediment are also bioavailable when their resuspension, decomposition and diffusion into the water column [24]. Therefore, the monitoring of sediment is very helpful to assess the pollution status of OTCs and to evaluate their potential environmental risks.

The aim of this work is to evaluate the pollution status and species of OTCs in sediments of typical fishing ports along the Chinese coast. A total of 52 surface sediment samples from nine fishing ports were collected. The concentrations and spatial distributions of BTs and PhTs were investigated. The potential risks of OTCs in the sediments were also discussed.

\section{Experimental}

\subsection{Sample collection}

The map of the study area and the locations of sampling sites are shown in Figure 1. A total of 52 surface sediment samples were collected from nine fishing ports or fishing districts in integrated harbors in 2007. Most of the selected fishing ports are located in relatively developed coastal areas covering the Yellow Sea, the East China Sea and the South China Sea. The surface sediments $(0-20 \mathrm{~cm}$ deep) were taken with a stainless steel grab sampler, then transferred into polyethylene bags, and kept in an icebox immediately. After shipping the samples back to the laboratory, the sediments were freeze-dried at $-45^{\circ} \mathrm{C}$, and ground until fine particles were obtained.

\subsection{Instrumentation}

The SPME procedure was conducted by manual SPME

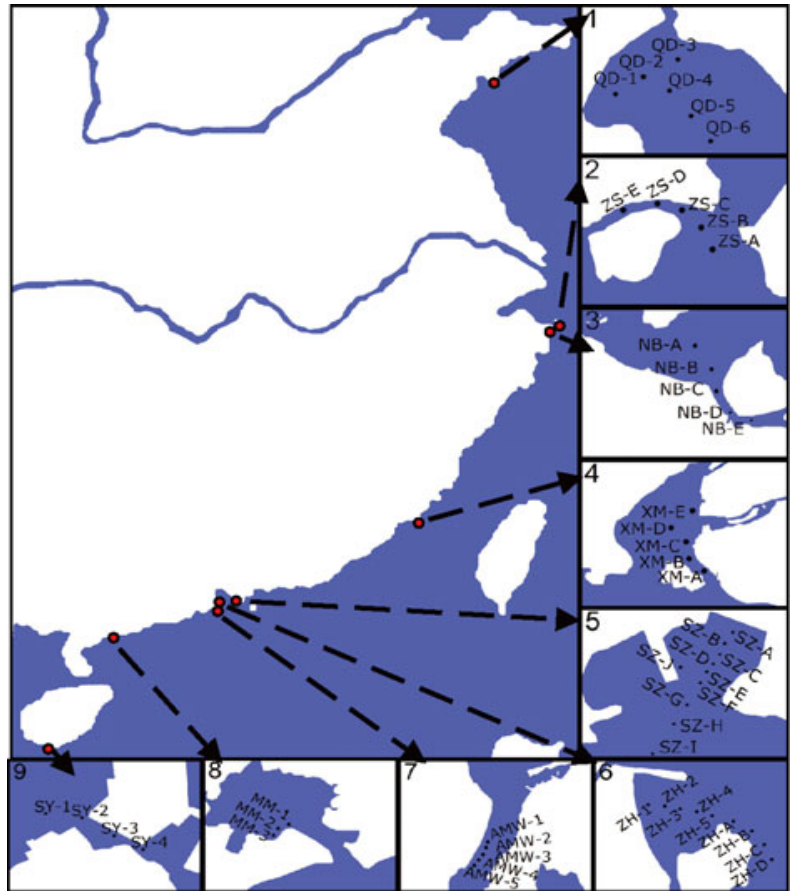

Figure 1 (Color online) The study area and sampling sites. 1, Shazikou fishing port in Qingdao; 2, Shenjiamen fishing port in Zhoushan; 3, Beilun fishing port in Ningbo; 4, Xigang fishing port in Xiamen; 5, Shekou fishing port in Shenzhen; 6, Xiangzhou fishing port in Zhuhai; 7, Wanzai fishing port in Macao; 8, Shuidong fishing port in Maoming; 9, Fishing subarea in Sanya harbor.

device with a fused silica fiber coated with $100 \mu \mathrm{m}$ polydimethylsiloxane (Supelco, USA). A GC-2010 gas chromatograph (Shimadzu, Japan) equipped with a flame photometric detector (FPD), and a tin filter was used for the qualitative and quantitative analysis. The separation was conducted on an Rtx- $5 \mathrm{~ms}$ capillary column $(30 \mathrm{~m} \times 0.25 \mathrm{~mm} \times 0.25 \mu \mathrm{m}$, Restek, USA) which was coated with $95 \%$ methyl silicone and $5 \%$ phenyl silicone. High purity of $\mathrm{He}(\geqslant 99.999 \%)$ was used as carrier gas. The column flow was $1.6 \mathrm{~mL} \mathrm{~min}^{-1}$, and the purge flow was $3.0 \mathrm{~mL} \mathrm{~min}{ }^{-1}$. The temperature of injector was held at $250^{\circ} \mathrm{C}$ with a $1: 10$ split injection mode. The oven temperature was initially held at $50^{\circ} \mathrm{C}$ for $2 \mathrm{~min}$, then increased at $20^{\circ} \mathrm{C} \mathrm{min}{ }^{-1}$ to $250^{\circ} \mathrm{C}$ and held for $3 \mathrm{~min}$. The temperature of FPD was set at $250^{\circ} \mathrm{C}$. The air and the hydrogen flows for the detector were both set at $70 \mathrm{~mL}$ $\mathrm{min}^{-1}$. Signal collection and process were conducted by the Shimadzu GC solution software.

\subsection{Reagents and standards}

All reagents used were of analytical reagent grade or better. Glassware was decontaminated overnight in 50\% (v/v) nitric acid solution and then rinsed with ultra pure water. The standards of monobutyltin (MBT) chloride (97\%), dibutyltin (DBT) chloride (96\%) and TBT chloride (96.5\%) were obtained from Dr. Ehrenstorfer Co. (Germany). Tripropyltin (TPrT) chloride (98\%) and triphenyltin (TPhT) 
chloride $(95 \%)$ were obtained from Merck (Germany). The stock standard solutions were prepared as $1 \mathrm{~g}(\mathrm{Sn}) \mathrm{L}^{-1}$ in methanol and stored at $-20^{\circ} \mathrm{C}$ in dark. Fresh working solutions of $1 \mathrm{mg}(\mathrm{Sn}) \mathrm{L}^{-1}$ were prepared daily by a proper dilution of the stock solution with ultra pure water. Methanol (HPLC grade) was purchased from J. T. Baker Chemicals Co. (USA). Sodium tetraethylborate $\left(\mathrm{NaBEt}_{4}, 98 \%\right)$ was purchased from Strem Chemicals (USA). Monophenyltin (MPhT) trichloride (98\%), diphenyltin (DPhT) dichloride (96\%) and tetrahydrofuran anhydrous (THF, 99.9\%) were obtained from Sigma Aldrich (USA). $\mathrm{NaBEt}_{4}$ was prepared as $20 \%(\mathrm{~m} / \mathrm{v})$ stock solution in THF and stored at $-20^{\circ} \mathrm{C}$ in refrigerator. Fresh working solutions of $2 \%(\mathrm{~m} / \mathrm{v})$ was prepared daily with ultra pure water. Sodium acetate (NaAc) (anhydrous, 99\%, Sigma Aldrich, USA) and acetic acid (HAc, 99.8\%, CNW Technology GmbH, Germany) were used for buffer preparation.

\subsection{Determination}

The analytical procedure was optimized from the methods described in reference [25]. Briefly, $1 \mathrm{~g}$ of sediment was weighed into a $15 \mathrm{~mL}$ glass tube. After it was mixed with a suitable amount of internal standard TPrT, $5 \mathrm{~mL}$ of $\mathrm{HCl}-$ methanol $(1: 20, \mathrm{v} / \mathrm{v})$ solution was added. The samples were vortexed for $1 \mathrm{~min}$ and sonicated for $20 \mathrm{~min}$ in an ultrasonic bath. The tube was then centrifuged for $5 \mathrm{~min}$ at 3000 $r \min ^{-1}$. The leachate was siphoned out with a Pasteur pipette, and the sediment layer was re-extracted with the same procedure. After centrifuged again, the leachate was combined.

Fifty microliter of leachate, $20 \mathrm{~mL}$ of ultra pure water and $5 \mathrm{~mL}$ of HAc-NaAc buffer $\left(0.2 \mathrm{~mol} \mathrm{~L}^{-1}, \mathrm{pH} 5.0\right)$ were transferred into a $50 \mathrm{~mL}$ glass vial closed with a septum in which a glass stir bar was put. After addition of $100 \mu \mathrm{L}$ $\mathrm{NaBEt}_{4}$ solutions $(2 \%, \mathrm{~m} / \mathrm{v})$ by a syringe into the vial, the SPME fiber was exposed to the headspace of the solution and the mixture was magnetically stirred at $750 \mathrm{r} \mathrm{min}^{-1}$ under $25^{\circ} \mathrm{C}$ for $15 \mathrm{~min}$. The SPME fiber was immediately injected into the GC inlet for $3 \mathrm{~min}$ of thermal desorption.

\subsection{Quality control}

The quantitative analysis was performed using the inner standard calibration method. Analytes-free sediment samples (pre-validated by the proposed method) were homogenized and used as matrix. After spiking with suitable amounts of OTCs standards, the derivatization and HS-
SPME procedure were performed as described above. All samples were analyzed in triplicate. The limits of detection (LOD) are 3.6, 2.3, 0.7, 5.1, 7.6, $6.9 \mathrm{ng}(\mathrm{Sn}) \mathrm{g}^{-1}$ for MBT, DBT, TBT, MPhT, DPhT, TPhT, respectively. Blanks were prepared following the same procedure with every five samples.

Certificated material PACS2 for marine sediment from the National Research Council of Canada (NRCC, Canada) was used to validate the method. As shown in Table 1, good agreements were obtained between the determined and certified values for butyltin compounds, confirming the accuracy of the analytical procedure.

\subsection{Statistical analysis}

The results were statistically analyzed to evaluate the relationships among the concentrations of OTCs using SPSS 8.0 (SPSS InC., USA) software.

\section{Results and discussion}

\subsection{Concentrations and species of OTCs}

The concentrations of different OTCs species in the sediment samples are shown in Table 2. The concentrations ranged from $<3.6$ to $194 \mathrm{ng}(\mathrm{Sn}) \mathrm{g}^{-1} \mathrm{dw}$ for MBT, $<2.3$ to $41.5 \mathrm{ng}(\mathrm{Sn}) \mathrm{g}^{-1} \mathrm{dw}$ for DBT, $<0.7$ to $86.0 \mathrm{ng}(\mathrm{Sn}) \mathrm{g}^{-1} \mathrm{dw}$ for TBT, $<5.1$ to $66.1 \mathrm{ng}$ (Sn) $\mathrm{g}^{-1} \mathrm{dw}$ for MPhT, respectively. In all samples, the concentrations of DPhT and TPhT were below the limit of detection (LOD). BTs were the main organotin species in the sediments. The percentages of BTs in total OTCs exceeded $70 \%$ in most samples except for those from Shazikou fishing port in Qingdao (Figure 2). Among BTs species, the concentration of MBT was the highest. Although MBT could be degraded from DBT and TBT, the concentrations of MBT in the samples collected near coastline were higher than those from the open water area. This indicated that MBT might have direct discharge sources from land areas, which could be transported into marine environment by runoff.

\subsection{Correlations among the OTCs species}

A correlation analysis was performed using SPSS 8.0 to evaluate the relationships among the concentration of various OTCs. The results are shown in Table 3. Significant correlations were found between MBT-DBT $(P<0.01, r=$

Table 1 Analytical results and recoveries of certified reference material-PACS2

\begin{tabular}{cccc}
\hline Species & Certified value $\left(\mathrm{mg} \mathrm{kg}^{-1}\right)$ & Determined value $\left(\mathrm{mg} \mathrm{kg}^{-1}\right)$ & Recovery $(\%)$ \\
\hline MBT & $0.6^{\mathrm{a}}$ & $0.521 \pm 0.069$ & 85.8 \\
DBT & $1.047 \pm 0.064$ & $0.957 \pm 0.142$ & 94.2 \\
TBT & $0.890 \pm 0.105$ & $0.863 \pm 0.167$ & 13.2 \\
\hline
\end{tabular}

a) Information value only. 
Table 2 The concentrations of OTCs in the sediment samples (ng ( Sn) $\left.g^{-1} d w\right)$

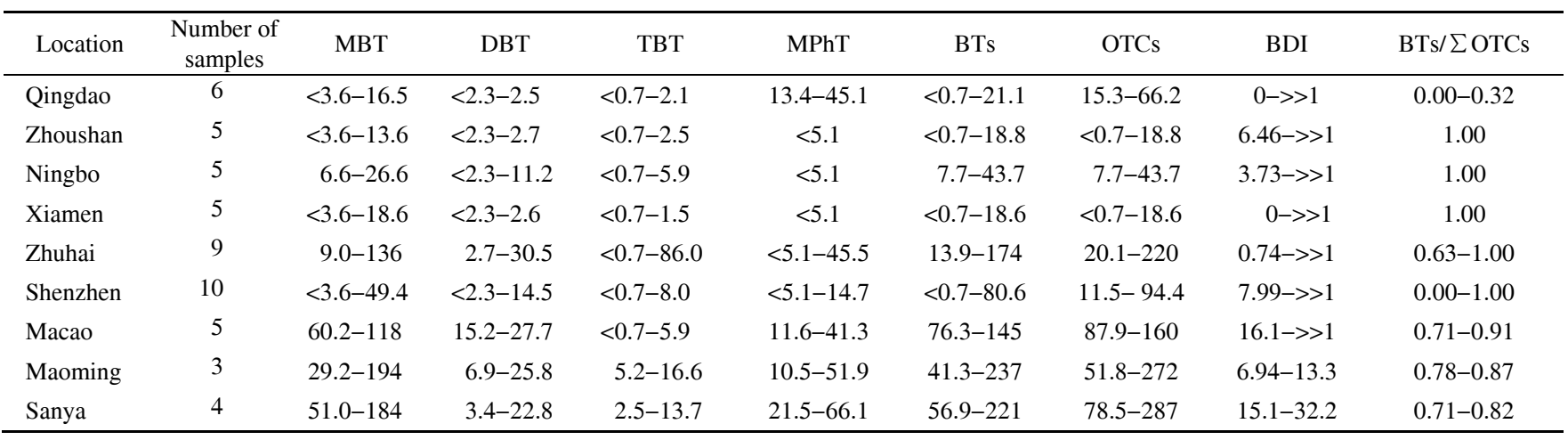

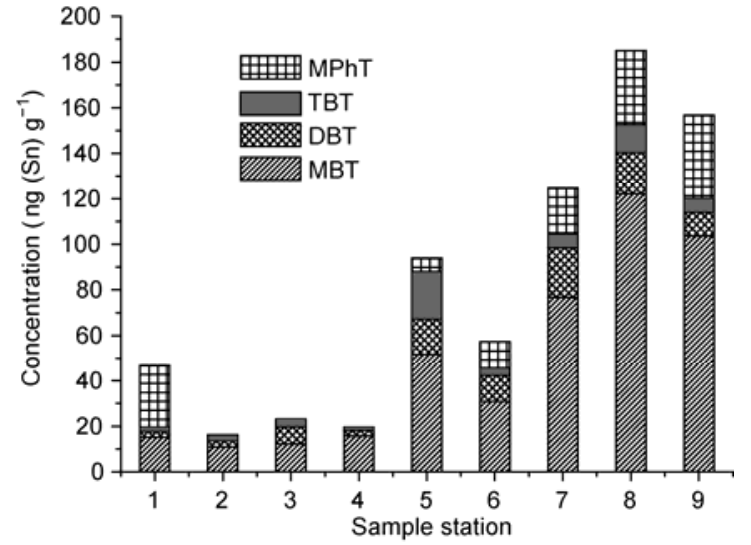

Figure 2 Composition of OTCs in the sediments from selected fishing ports.

Table 3 Pearson correlation coefficients between the concentrations of OTCs

\begin{tabular}{llllll}
\hline & MBT & DBT & TBT & MPhT & BTs \\
\hline DBT & $0.580^{\text {a) }}$ & & & & \\
TBT & 0.208 & $0.490^{\text {b) }}$ & & & \\
MPhT & $0.666^{\text {a) }}$ & 0.373 & 0.007 & & \\
BTs & $0.954^{\text {a) }}$ & $0.741^{\text {a) }}$ & $0.504^{\text {a) }}$ & $0.604^{\text {a) }}$ & \\
OTCs & $0.959^{\text {a) }}$ & $0.684^{\text {a) }}$ & $0.435^{\text {b) }}$ & $0.705^{\text {a) }}$ & $0.983^{\text {a) }}$ \\
\hline
\end{tabular}

a) Correlation is significant at the 0.01 level (2-tailed); b) correlation is significant at the 0.05 level (2-tailed).

$0.58)$, MBT-MPhT $(P<0.01, r=0.67)$, and DBT-TBT $(P<$ $0.05, r=0.49)$, respectively. But the correlations between MBT and TBT, MPhT and TBT were not significant. The results are differed from some literatures [7,14], in which high correlations between MBT and TBT were obtained, and MBT were thought as a degraded product of TBT. However, the data in the present study indicated the possible direct discharge of MBT to coastal environments.

To further prove this, the degradation of TBT was evaluated using the method proposed by Díez et al. [24]. In marine environments, TBT may degrade to their derivatives MBT and DBT affected by many factors [1]. Díez et al. [24] thought that the ratio of $(\mathrm{MBT}+\mathrm{DBT}) / \mathrm{TBT}$, called BT degradation index (BDI), could be used to estimate the time of pollution occurred in the environment. If the BDI value is less than 1 , the TBT in sediment could be considered as recent contamination. In this work, BDI values for most the sediments were $>1$ (Table 2 ), indicating that there was little TBT input in recent years at the sampling areas. It was noticed that the values of BDI in this work were much higher than those in other studies summarized by Chen et al. [14]. This further confirmed the direct discharge of MBT to coastal water environments. Because the concentrations of DPhT and TPhT were below the LOD in all samples, the degradation of PhTs was not evaluated. However, the high detection rate of MPhT in the sampling stations 1, 5-9 indicated the prevalent use of PhTs-contained products in the surrounding regions [1].

\subsection{Spatial distributions of OTCs}

The concentrations of OTCs in the sediments varied widely among different locations. The highest concentration (287 $\mathrm{ng}(\mathrm{Sn}) \mathrm{g}^{-1} \mathrm{dw}$ ) of total OTCs was found at the fishing subarea in Sanya harbor, indicating intensive input of OTCs in this area. As shown in Figure 3, the concentrations of BTs

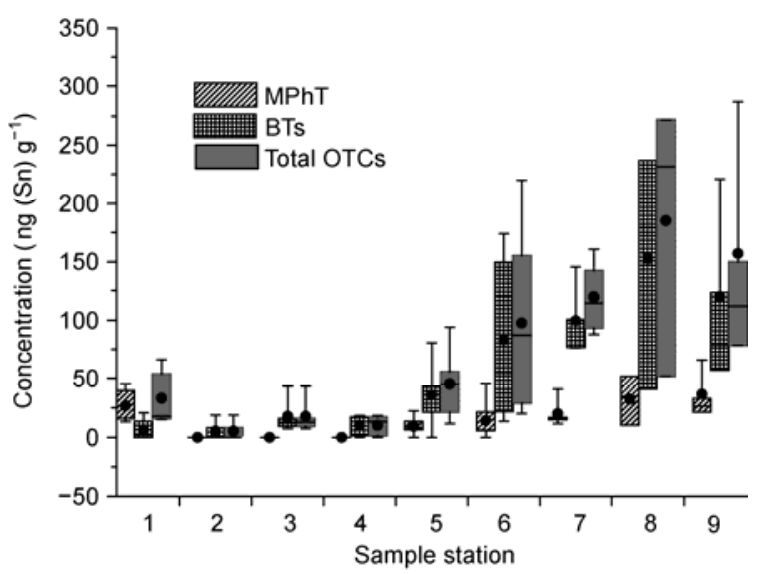

Figure 3 Distribution of OTCs in the sediments from selected fishing ports. 
in sediments from stations 5-9 located in the South China Sea were much higher than those from other sampling stations. MPhT were detectable in most samples collected from station 1 located in the Yellow Sea, and stations 5-9 located in the South China Sea. The concentrations of MPhT were relatively lower in the samples from stations 2-4 located in the East China Sea compared with other locations. As a whole, the contamination of OTCs was more serious in sampling stations 5-9 than other stations (Figure 3 ). This was consistent with the economic development in these areas. For example, sampling stations 5-8 are located in the Pearl River Estuary, an area characterized by most dense harbors, and most heavy ocean traffic in China.

\subsection{Comparison with other studies}

Surveys on BTs pollution in Chinese coastal sediments were mainly focused in the East China Sea and the South China Sea. The sampling station 4 in Xigang Port of Xiamen, was almost the same site with a previous reference [26]. The levels of BTs determined in this work was similar with those reported, whereas the compositions of BTs species were different. The percentages of MBT and DBT were much higher than those reported in the reference [26]. This was probably because of the decomposition of TBT to DBT and MBT, and direct discharge of MBT as mentioned above. As a whole, compared with those values reported in China's coastal areas, the concentrations of MBT and DBT in sampling stations 5-9 of this work were similar to those in Huiyang Port, Shenzhen and Hong Kong [18,27], but higher than those reported in Xiamen Port, Shantou Port, Victoria Harbor (Hong Kong), Jiulongjang estuary, Minjiang estuary and Zhujiang estuary [26,27]. However, the levels of TBT in these sites were much lower than that in Shenzhen [18], Hong Kong [28] and the Pearl River Delta [29], respectively. The levels of BTs in sampling stations 1-4 of this study were similar to those reported in Shantou Port and Victoria Harbor in Hong Kong [26,27].

In comparison with those values reported in other countries, the levels of BTs obtained in this study were similar with those in São Vicente Estuary (Brazil) [13], Coast (Vietnam) [30], North coast of Kyoto (Japan) [31], but significantly lower than those in Kochi Harbor (India) [32], estuaries of Gipuzkoa (Spain) [33], Northern Adriatic Sea (Slovenia) [34], Santa Catarina Harbors (Brazil) [13] and coast of Mediterranean (Spain) [24].

The comparison of BTs determined in this work with those reported in literatures is shown in Table 4. The concentrations of PhTs were not included because lacking of published data.

\subsection{Potential environmental risks}

Although there was no uniform sediment quality standard implemented for OTCs, several works have proposed their own pollution classification methods. Waite et al. [35] ranked TBT levels in sediments as lightly contaminated (4.1-20.5 ng ( $\mathrm{Sn}) \mathrm{g}^{-1}$ ), medium contaminated (24.6-80.2 $\mathrm{ng}(\mathrm{Sn}) \mathrm{g}^{-1}$ ), highly contaminated (123-410 ng (Sn) $\mathrm{g}^{-1}$ ) and likely to contain paint particles (higher than $410 \mathrm{ng}(\mathrm{Sn})$ $\left.\mathrm{g}^{-1}\right)$. According to this classification, only one sample (ZH-1 in sampling station 6) was medium contaminated, and 12 samples (NB-B in sampling station 3; SZ-B in sampling station 5; ZH-A, ZH-B ZH-C, ZH-D in sampling station 6; AMW-2 in sampling station 7; MM-1, MM-2, MM-3 in sampling station 8; SY-2, SY-4 in sampling station 9)

Table 4 Comparison of the concentrations of OTCs in sediments from different bays, estuaries and harbors (ng (Sn) $\left.\mathrm{g}^{-1}\right)^{\text {a) }}$

\begin{tabular}{|c|c|c|c|c|c|}
\hline Locations & MBT & DBT & TBT & Country & Reference \\
\hline \multicolumn{6}{|c|}{ OTCs concentrations in sediments from bays, estuaries and harbors in China } \\
\hline Fishing Ports & $<3.6-194$ & $<2.3-41.5$ & $<0.7-86.0$ & China & This work \\
\hline Xiamen Port & 11.3 & n.d. & 31.4 & China & [27] \\
\hline Shantou Port & 10.9 & 0.1 & 1.4 & China & [27] \\
\hline Huiyang Port & 50.8 & 0.1 & 2.6 & China & {$[27]$} \\
\hline Pearl River Delta & n.a. & n.a. & $0.7-155$ & China & [29] \\
\hline \multicolumn{6}{|c|}{ OTCs concentrations in sediments from bays, estuaries and harbors in other countries } \\
\hline Santa Catarina Harbors & n.d. -312 & n.d.-394 & n.d. -1137 & Brazil & {$[13]$} \\
\hline São Vicente Estuary & n.d. -161 & n.d. to n.q. & n.d. to n.q. & Brazil & [13] \\
\hline Mediterranean coast & $7-415$ & $40-1790$ & $76-4487$ & Spain & {$[24]$} \\
\hline Coast & $<0.04-11$ & $0.64-4.6$ & $0.89-28$ & Vietnam & {$[30]$} \\
\hline Kochi Harbors & n.a. & n.d. -470 & $4.5-16816$ & India & {$[32]$} \\
\hline Gipuzkoa estuaries & $860-2870$ & $150-710$ & $80-5480$ & Spain & {$[33]$} \\
\hline Northern Adriatic Sea & $<1.6-934$ & $<1.6-702$ & $<2.5-1995$ & Slovenia & {$[34]$} \\
\hline
\end{tabular}

a) n.d., not detectable; n.q., not qualified; n.a., not available. 
were lightly contaminated. Other 39 samples could be considered no pollution of TBT. Dowson et al. [36] suggested a more stringent environmental quality criterion on TBT, including no contamination (below $1.2 \mathrm{ng}(\mathrm{Sn}) \mathrm{g}^{-1} \mathrm{TBT}$ ), light contamination (1.2-8.2 $\mathrm{ng}(\mathrm{Sn}) \mathrm{g}^{-1}$ TBT), moderate contamination (8.2-41 ng (Sn) $\mathrm{g}^{-1}$ TBT), high contamination (41-205 ng (Sn) $\mathrm{g}^{-1}$ TBT), and severe contamination (above $\left.205 \mathrm{ng}(\mathrm{Sn}) \mathrm{g}^{-1} \mathrm{TBT}\right)$. When this classification was applied, one sample (ZH-1 in sampling station 6) was changed into high contamination, and five samples (MM-1, MM-3 in sampling station 8; ZH-B, ZH-C in sampling station 6, SY-2 in sampling station 9) were classified to moderate contamination. As a whole, $48.1 \%$ of samples were regarded as light contamination, and $40.4 \%$ of samples could be considered as no contamination. Therefore, the levels of TBT in the study areas could be considered light contamination.

For adverse biological effect concern, the ecotoxicological risk of sediment bounded TBT (TBT bounded to sediment) on benthic organisms was evaluated based on references [37-40]. Burton et al. [37] established 5 and 70 $\mathrm{ng}(\mathrm{Sn}) \mathrm{g}^{-1}$ of TBT as low and high trigger values, respectively. The values in about $23 \%$ sediment samples, most of which located in sampling station 6 and 8 , were above the low trigger value. Only one sample (86.0 ng (Sn) $\mathrm{g}^{-1}$, ZH-1 in sampling station 5) exceeded the high trigger value. The chronic toxic effects on amphipods and polychaetes were further investigated in this sample according to the value of $41.2 \mathrm{ng}(\mathrm{Sn}) \mathrm{g}^{-1}$ in vivo sediment toxicity test [38]. The BTs in all samples were lower the value of $300 \mathrm{ng}(\mathrm{Sn}) \mathrm{g}^{-1}$ which could cause chronic effects on benthic clam $[39,40]$. Therefore, most sampling stations in this work showed low ecotoxicological risk of sediment-bounded TBT to benthic organisms. However, monitoring the OTCs in coastal areas is still indispensable because their spatially heterogeneity, and possible on-going input to coastal sediments.

\section{Conclusions}

BTs and PhTs in surface sediments from nine typical fishing ports along the Chinese coast were studied. The highest concentration $\left(287 \mathrm{ng}(\mathrm{Sn}) \mathrm{g}^{-1} \mathrm{dw}\right.$ ) of total OTCs was recorded at fishing subarea in Sanya harbor, indicating intensive inputs of organotin-containing products to the marine environment. BTs were the main species in the sediments except for those collected from Shazikou fishing port in Qingdao. MBT was found to be the major component, suggesting various sources of MBT besides antifouling paints. Spatially, the pollution of BTs in sediments were more serious in fishing ports along the South China Sea, including Shekou fishing port in Shenzhen, Xiangzhou fishing port in Zhuhai, Wanzai fishing port in Macao, Shuidong fishing port in Maoming and fishing subarea in Sanya harbor, than those along the East China Sea and the Yellow Sea.
MPhT was prevalent in most sampling stations. In general, the concentrations of BTs in the sediments were not very high. The concentrations of TBT in most samples were generally low with limited environmental and ecotoxicological risks. However, monitoring of organotin pollution in coastal areas is still important because of their heterogeneity of distribution and possible continued input.

This work was supported by the National High Technology Research and Development Program of China (2009BAK61B04), the CAS/SAFEA International Partnership Program for Creative Research Teams (KZCX2-YWT001), the Major Program of the National Natural Science Foundation of China (20890111) and the National Natural Science Foundation of China (20977107, 40802087).

1 Hoch M. Organotin compounds in the environment-An overview. Appl Geochem, 2001, 16: 719-743

2 Gallego-Gallegos M, Munoz-Olivas R, Martin-Esteban A, et al. Synthesis and evaluation of molecularly imprinted polymers for organotin compounds: A screening method for tributyltin detection in seawater. Anal Chim Acta, 2005, 531: 33-39

3 de Carvalho Oliveira R, Santelli R E. Occurrence and chemical speciation analysis of organotin compounds in the environment: A review. Talanta, 2010, 82: 9-24

4 Gibbs P, Bryan G. Reproductive failure in the gastropod nucella lapillus associated with imposex caused by tributyltin pollution: A review. In: Champ $M$ A, Seligman $P$ F, eds. OrganotinEnvironmental Fate and Effects. London: Chapman \& Hall, 1998. 259-281

5 Zhou Q F, Li Z Y, Jiang G B, et al. Preliminary investigation of a sensitive biomarker of organotin pollution in Chinese coastal aquatic environment and marine organisms. Environ Pollut, 2003, 125: 301-304

6 Shi G, Chen D, Zhai G, et al. The proteasome is a molecular target of environmental toxic organotins. Environ Health Persp, 2009, 117: 379-386

7 Filipkowska A, Kowalewska G, Pavoni B, et al. Organotin compounds in surface sediments from seaports on the Gulf of Gdańsk (southern Baltic coast). Environ Monit and Assess, 2011, 182: 455-466

8 Gipperth L. The legal design of the international and European Union ban on tributyltin antifouling paint: Direct and indirect effects. J Environ Manage, 2009, 90: S86-S95

9 Bitonti C P H. Exporting ignorance: Canada's opposition to the regulation of the International Chrysotile Asbestos Trade under the Rotterdam Convention. Asper Rev Inter Bus Trade Law, 2009, 9: 171-199

10 Xie W, Wang X H, Zheng J S, et al. Occurrence and distribution of organotin compounds in Thais clavigera from Xiamen coast (in Chinese). Environ Sci, 2010, 31: 1072-1078

11 Okoro H K, Fatoki O S, Adekola F A, et al. Sources, environmental levels and toxicity of organotin in marine environment-A review. Asian J Chem, 2011, 23: 473-482

12 Hu J Y, Zhang Z B, Wei Q W, et al. Malformations of the endangered Chinese sturgeon, Acipenser sinensis, and its causal agent. Proc Natl Acad Sci USA, 2009, 106: 9339-9344

13 de Oliveira C R, dos Santos D, dos Santos Madureira L A, et al. Speciation of butyltin derivatives in surface sediments of three southern Brazilian harbors. J Hazard Mater, 2010, 181: 851-856

14 Chen C F, Kao C M, Dong C D, et al. Butyltin contamination in sediments and seawater from Kaohsiung Harbor, Taiwan. Environ Monit Assess, 2010, 169: 75-87

15 Jiang G B, Zhou Q F, Liu J Y, et al. Occurrence of butyltin compounds in the waters of selected lakes, rivers and coastal environments from China. Environ Pollut, 2001, 115: 81-87 
16 Cao D, Jiang G B, Zhou Q F, et al. Organotin pollution in China: An overview of the current state and potential health risk. J Environ Manage, 2009, 90: S16-S24

17 Yang R Q, Zhou Q F, Liu J Y, et al. Butyltins compounds in molluscs from Chinese Bohai coastal waters. Food Chem, 2006, 97: 637-643

18 Zhou Q F, Jiang G B, Liu J Y. Organotin pollution in China. Sci World J, 2002, 2: 655-659

19 Shi H H, Huang C J, Zhu S X, et al. Generalized system of imposex and reproductive failure in female gastropods of coastal waters of mainland China. Mar Ecol-Prog Ser, 2005, 304: 179-189

20 Gadd G M. Microbial interactions with tributyltin compounds: Detoxification, accumulation, and environmental fate. Sci Total Environ, 2000, 258: 119-127

21 Waldock M J, Thain J E, Smith D, et al. The degradation of TBT in estuarine sediments. Proc 3rd Int Organotin Symp, Monaco, 1990, 46-49

22 Maguire R J. Environmental aspects of tributyltin. Appl Organomet Chem, 1987, 1: 475-498

23 Evans S M. Tributyltin pollution: The catastrophe that never happened. Mar Pollut Bull, 1999, 38: 629-636

24 Díez S, Abalos M, Bayona J M. Organotin contamination in sediments from the Western Mediterranean enclosures following 10 years of TBT regulation. Water Res, 2002, 36: 905-918

25 Cui Z, Zhang K, Zhou Q, et al. Determination of methyltin compounds in urine of occupationally exposed and general population by in situ ethylation and headspace SPME coupled with GC-FPD. Talanta, 2011, 85: 1028-1033

26 Yuan D X, Yang D N, Wade T L, et al. Status of persistent organic pollutants in the sediment from several estuaries in China. Environ Pollut, 2001, 114: 101-111

27 Huang C J, Dong Q X, Lie Z, et al. An investigation of organotin compound contamination in three harbors along southeast coast of China (in Chinese). Acta Oceanol Sin, 2005, 27: 57-63

28 Lau M M M. Tributyltin antifoulings-A threat to the Hong-Kong marine-environment. Arch Environ Con Tox, 1991, 20: 299-304

29 Zhang G, Yan J, Fu J M, et al. Butyltins in sediments and biota from the Pearl River Delta, South China. Chem Spec Bioavailab, 2003, 14: 35-42

30 Midorikawa S, Arai T, Harino H, et al. Concentrations of organotin compounds in sediment and clams collected from coastal areas in Vietnam. Environ Pollut, 2004, 131: 401-408

31 Ohji M, Arai T, Midorikawa S, et al. Distribution and fate of organotin compounds in Japanese coastal waters. Water Air Soil Pollut, 2007, 178: 255-265

32 Bhosle N B, Garg A, Harji R, et al. Butyltins in the sediments of Kochi and Mumbai harbours, west coast of India. Environ Int, 2006, 32: $252-258$

33 Arambarri I, Garcia R, Millan E. Assessment of tin and butyltin species in estuarine superficial sediments from Gipuzkoa, Spain. Chemosphere, 2003, 51: 643-649

34 Nemanic T M, Milacic R, Scancar J. A survey of organotin compounds in the Northern Adriatic Sea. Water Air Soil Pollut, 2009, 196: 211-224

35 Waite $\mathrm{M}$ E, Waldock M J, Thain $\mathrm{J} \mathrm{E}$, et al. Reductions in TBT concentrations in UK estuaries following legislation in 1986 and 1987. Mar Environ Res, 1991, 32: 89-111

36 Dowson $\mathrm{P} \mathrm{H}$, Bubb J M, Lester $\mathrm{J}$ N. Temporal distribution of organotins in the aquatic environment -5 years after the 1987 UK retail Ban ban on TBT based antifouling paints. Marine Pollut Bull, 1993, 26: 487-494

37 Burton E D, Phillips I R, Hawker D W. In-situ partitioning of butyltin compounds in estuarine sediments. Chemosphere, 2005, 59: 585-592

38 Matthiessen $\mathrm{P}$, Thain $\mathrm{J}$ E. A method for studying the impact of polluted marine-sediments on intertidal colonising organisms-Tests with diesel-based drilling mud and tributyltin antifouling paint. Hydrobiologia, 1989, 188: 477-485

39 Langston W J, Burt G R. Bioavailability and effects of sedimentbound TBT in deposit-feeding clams, Scrobicularia-Plana. Mar Environ Res, 1991, 32: 61-77

40 Ruiz J M, Bryan G W, Gibbs P E. Bioassaying the toxicity of tributyltin (TBT)-polluted sediment to spat of the bivalve scrobicularia-plana. Mar Ecol-Prog Ser, 1994, 113: 119-130

Open Access This article is distributed under the terms of the Creative Commons Attribution License which permits any use, distribution, and reproduction in any medium, provided the original author(s) and source are credited. 